\title{
Fish Bone in Fistula in Ano - Report of a Rare and Interesting Case
}

\author{
Nikita ${ }^{1}$, K.S. Shahi ${ }^{2}$, Geeta Bhandari ${ }^{3}$ \\ ${ }^{1,2}$ Department of Surgery, Government Medical College, Haldwani, Uttarakhand, India. \\ ${ }^{3}$ Department of Anaesthesiology, Government Medical College, Haldwani, Uttarakhand, India.
}

\section{INTRODUCTION}

Anal fistulas are a very common surgical problem that is seen in our day-to-day practice. Anal fistula is caused by idiopathic crypto-glandular infections in more than $90 \%$ of cases. The major complications include peritonitis, perforation and perianal abscesses and fistula. There are very few cases of anal fistula caused by an ingested foreign body reported in the literature. Here we report a rare case of a 35 -year-old army man who had an anal fistula with impacted fish bone. The aim of this case report is to raise a suspicion of a foreign body in case of a chronic non healing perianal fistula and to avoid injury to surgeons' fingers while exploring or performing a digital rectal examination.

Perianal abscess and fistula are a cause of significant morbidity worldwide and have been documented since the time of Hippocrates (460 BC). Anorectal sepsis accounts for $0.5-1 \%$ of all surgical admissions and constitutes $20-25 \%$ of those for colorectal disorders. ${ }^{1}$ Except for unusual disease, fistula in ano originates from infection in the anal crypts of Morgagni, forming an abscess. The abscess, when it opens, result in a tract leading to the skin surface. This brief report presents a case of fistula-in-ano with unusual aetiology that is rarely reported in literature.

\section{PRESENTATION OF CASE}

A 35 years old army man presented with the history of painful swelling around anus for six months for which he took treatment elsewhere. Swelling and pain used to subside after the treatment but discomfort during defecation persisted. For last 5-6 days he developed throbbing pain which increased during sitting and coughing. He noticed pus discharge from the perianal swelling. General physical examination revealed an otherwise healthy male without any systemic abnormality.
Corresponding Author: Dr. K.S. Shahi,

Department of Surgery, Government Medical College, Haldwani, Nainital, Uttarakhand, India. E-mail: kedar_shahi@rediffmail.com

DOI: $10.14260 / j e m d s / 2022 / 86$

How to Cite This Article: Nikita, Shahi KS, Bhandari G. Fish bone in fistula in ano - report of a rare and interesting case. J Evolution Med Dent Sci 2022;11(03):439-441, DOI: 10.14260/jemds/2022/86

Submission 27-02-2019,

Peer Review 07-02-2022,

Acceptance 14-02-2022,

Published 25-02-2022.

Copyright (C) 2022 JEMDS. This is an open access article distributed under Creative Commons Attribution License [Attribution 4.0 International (CC BY 4.0)] 


\section{CLINICAL DIAGNOSIS}

Local examination was suggestive of perianal abscess with fistula formation (Fig. 1).

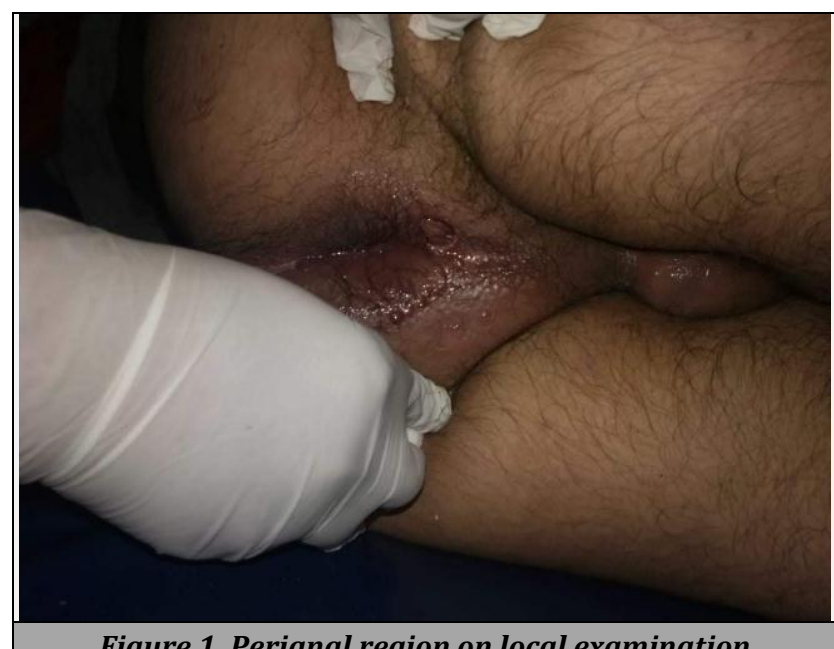

Figure 1. Perianal region on local examination

\section{DIFFERENTIAL DIAGNOSIS}

Perianal abscess or fistula in ano or ischiorectal abscess.

\section{DISCUSSION OF MANAGEMENT}

He was scheduled for examination under anaesthesia and anal fistulectomy. Per operatively a foreign body (fish bone) was seen inside the perianal abscess cavity, and a small opening connecting to the anal canal could be identified. We treated the case as an anal fistula and fistulotomy performed after extracting the fish bone from the fistula (Fig. 2).

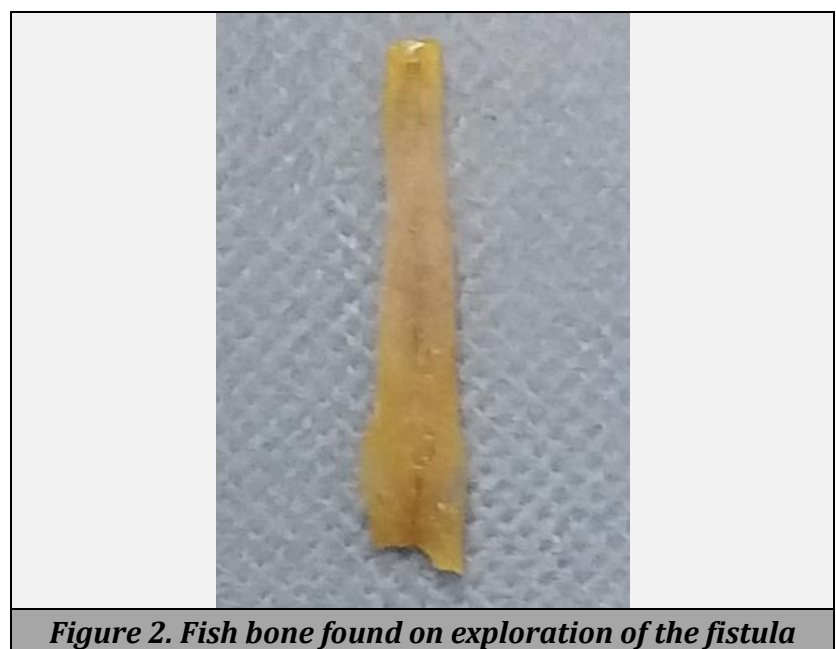

DISCUSSION

The anal canal is a very unusual site of impaction for foreign body by ingestion. Ingestion of an unusual foreign body occurs rarely but most foreign bodies pass through the gastrointestinal tract without significant complications and morbidity. ${ }^{2}$ In some cases the presence of foreign bodies in the gastrointestinal tract results in acute abdomen requiring emergency surgical intervention. ${ }^{2}$ Ingested foreign bodies like dentures, chicken bones, fish bones, wires, and toothpicks can cause perforation of the gastrointestinal system.2,3

Perianal abscess and fistula are the same condition, the abscess being the acute phase and the fistula is the chronic phase. ${ }^{4}$ More than $90 \%$ of perianal abscesses are due to cryptoglandular infection. [4] Associated diseases predisposing to anorectal sepsis includes Crohn's disease, ulcerative colitis, pulmonary tuberculosis, actinomycosis, lymphogranuloma venereum and rectal cancer. 5 The incidence of fistula-in-ano following anorectal abscess was $26 \%$ in the acute phase or as a sequalae. ${ }^{6}$ Few cases of mediastinitis, peritonitis or intraabdominal abscesses secondary to perforation by ingested foreign body are reported in literature. The common sites of impaction and perforation include the appendix, caecum and Meckel's diverticulum. ${ }^{7}$ The incidence of bezoars or impacted foreign body is higher in patients with previous history of operative manipulation of the gastrointestinal tract. ${ }^{8}$ Risk factors like anal stenosis and spastic anal sphincter predisposes to foreign body impaction in the anal canal.

Careful inspection and digital rectal examination can establish the diagnosis of the abscess and an associated fistula, but not always demonstrate the presence of the impacted foreign body. ${ }^{9}$ Occasionally, plain X-Ray is diagnostic and helpful in preventing sharp penetrating injury to the physician's examining finger. However, X-rays are only indicated when per-anal insertion of a foreign body is suspected. Although magnetic resonance imaging of the rectum and anus is useful in the assessment of complex perianal sepsis, ${ }^{10}$ it is unlikely to be used in a setting such as occurred in this case and its role in the detection of unintentional foreign body is unknown. Early, drainage and adequate exploration of the abscess cavity can help remove the offending cause and provide cure. Fish bone are sharp objects and they can get lodged in the aerodigestive tract and cause complications, although this is rare about $1-3 \%$. The associated complications are catastrophic including cervical abscess, mediastinitis, oesophageal-carotid fistula, lung abscess if it gets into the airway and perforated bowel as it passes through intestinal tract. ${ }^{11}$ The most common site for fish bone impaction is the oesophagus and it comprises $60 \%$ of oesophageal foreign bodies. ${ }^{12}$ PD Maldjian in 1999, reported two cases of small bowel perforation secondary to ingested fish bones. In one of these, the findings from computed tomography leads to the correct diagnosis preoperatively. ${ }^{10}$ In our case, a fish bone ingested by the patient was impacted in the anal canal. The force exerted by the anal sphincter during defecation or probably by the evacuated faecal matter resulted in this sharp object being pushed through the anal canal with its pointed end leading into the perianal tissue. Subsequently, infection resulted in abscess and fistula formation. A review of the literature revealed that that fish bones are not known to perforate the large intestine or the anal canal and not known to cause perianal sepsis. Therefore, it is unusual for a sharp fish bone in the gastrointestinal tract to penetrate the anal canal with its strong musculature and to cause perianal suppuration. 


\section{CONCLUSION}

Finding a fish bone or any other sharp objects in the fistulous tract is rare and unexpected event therefore a high index of suspicion is necessary to prevent an injury to the exploring fingers of the operator. Foreign bodies like fish, chicken, mutton bone etc should be considered as a cause of perianal fistula and abscesses.

\section{REFERENCES}

[1] Hyman N. Anorectal abscess and fistula. Prim Care 1999;26(1):69-80.

[2] Goh BKP, Chow PKH, Quah HM, et al. Perforation of the gastrointestinal tract secondary to ingestion of foreign bodies. World J Surg 2006;30(3):372-7.

[3] Polat AK, Polat AV, Erzurumlu Z, et al. An accidentally ingested mandibular prosthesis was extempt from surgery. Chirurgia (Bucur) 2012;107(6):805-8.

[4] Hassan A, Saboor MA, Haider F, et al. Ingested fish bone, unusual cause of perianal sepsis: a case report. Bahrain Med Bull 2001;23(2):98-9.
[5] Chris M, Paul F. Anorectal sepsis, abscess and fistula. J Surgery (Quarter edition) 1998;41:69-72.

[6] Henrichsen S, Christiansen J. Incidence of fistula-in-ano complicating anorectal sepsis: a prospective study. Br J Surg 1986;73(5):371-2.

[7] Wong JHL, Suhaili DN, Kok KYY. Fish bone perforation of Meckel's diverticulum: a rare event? Asian J Surg 2005;28(4):295-6.

[8] Leung E, Barnes R, Wong L. Bezoar in gastro-jejunostomy presenting with symptoms of gastric outlet obstruction: a case report and review of the literature. J Med Case Reports 2008;2:323.

[9] Seow C, Leong AFPK, Goh HS. Acute anal pain due to ingested bone. Int J Colorectal Dis 1991;6(4):212-3.

[10] Maldjian PD. Case report: Perforation of the small bowel from fish bone ingestion: CT findings. J Emerg Radiol 1999;6:361-3.

[11] Lloyd-Jones W, Giles GR. The colon, rectum and anal canal. In: Cuschieri A, ed. Essential surgical practice. $3^{\text {rd }}$ edn. London: Butterworth Heinemann 1995:617.

[12] Herranz-Gonzalez J, Martenz-Vidal J, Garcia-Sarandeses A, et al. Esophageal foreign body in adults. Otolaryngol Head Neck Surg 1991;105(5):649-54. 